\title{
Interacción Candida albicans-Hospedero: un proceso complejo en el que la inmunidad innata juega un importante papel
}

\author{
(Candida albicans-host interaction: a complex process in which the innate immunity play \\ an important role)
}

\author{
Claudio Alburquenque $0^{1,2}$., Cecilia V. Tapia $\mathrm{P}^{2 *}$. \\ 1 Escuela de Tecnología Médica Universidad Mayor \\ 2 Programa de Microbiología y Micología, ICBM, Facultad de medicina \\ Universidad de Chile. Av. Independencia 1027. \\ Teléfono: +56-2-29786145, Fax: +56-2-27355855 \\ *Autor para correspondencia: cetapia@med.uchile.cl
}

RECIBIDO: 10-12-13

APROBADO:20-12-13

Palabras clave: Candida, inmunidad innata, PRRs, PAMPS

Key words: Candida, innate immunity, PRRs, PAMPS

\section{RESUMEN}

Candida albicans es una levadura comensal, que bajo ciertas circunstancia puede convertirse en patógeno. La capacidad de cambiar se forma constituye un factor de virulencia, permitiéndole a la levadura invadir y diseminarse. El sistema inmune innato es capaz de reconocer las diferentes morfologías de $C$. albicans activando receptores (PRRs) que reconocen PAMPs o patrones moleculares conservados. Las células inmunes más importantes son los macrófagos y los neutrófilos que desencadenan una respuesta efectoraa través de la fagocitosis y la activación de estrés oxidativo contra $C$. albicans. Las células dendríticas, por su parte expresan la mayoría de los PRRs involucrados en el reconocimiento de C. albicans activando la secreción de citoquinas hacia una respuesta tipo $\mathrm{T}_{1} 1$ (inducida por INF tipo1, IL-12, INFy, ), $\mathrm{T}_{\text {rog }}$ (inducida por TGF $\beta$, IL-10) y $\mathrm{TH}_{17}$ (inducida por IL-23, IL6). Las células epiteliales no sólo constituyen una barrera física frente a la infección por $C$. albicans, sino son fundamentales en el reconocimiento primario de este microorganismo. Mediante una respuesta bifásica estas células activan diferencialmente, vías de trans-ducción de señales que determinan que no se active una respuesta de citoquinas frente a la presencia de blastoconidios (forma comensal) y que se active frente a presencia de hifas (forma invasora). Por su parte, C. albicans es capaz de desarrollar mecanismos evasivos de la respuesta inmune. Esta compleja interacción y hongo-hospedero determina si el hospedero será capaz de eliminar a este microorganismo o si éste finalmente invadirá expresando su virulencia.

\section{ABSTRACT}

Candida albicans is a comensal microorganism that under certain circumstances is able to transform into a pathogen. This ability to switch constitute a virulence factor that $C$. albicans uses to invade and spread. The innate immune system recognize the different forms of C. albicans activating receptors (PRRs) that recognize PAMPs or conserved molecular patterns. The most important immune cells are macrophages and neutrophils that generate an effector response through phagocytosis and oxidative burst against $C$. albicans. Dendritic cells express the most of PRRs involved in the recognition of $C$. albicans activating the cytokines synthesis forward to a $\mathrm{T}_{4} 1$ (induced by INF tipo1, IL-12,

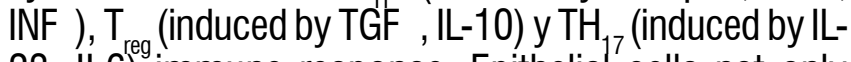
23, IL6) immune response. Epithelial cells not only constitute a physical barrier against $C$. albicans, but they are crucial in the first recognition of this microorganism. Through a biphasic response these cells differentially activate pathways that determine a no cytokine response when blastoconidia (commensal form) is present and an inflammatory response in presence of hyphae (pathogenic form). C. albicans develops immune evasive mechanism. This complex host-fungi interaction determines if the host will eradicate the infection or if this microorganism will invade the host, expressing it virulence. 
Candida albicans es una levadura comensal que coloniza el tracto gastrointestinal y genitourinario en un 30 a $50 \%$ del ser humano. Sin embargo, bajo ciertas condiciones ambientales 0 alteraciones de la inmunidad del hospedero, expresa factores de virulencia y se convierte en patógeno [1] [2].

Aproximadamente un $15 \%$ de las infecciones asociadas a la atención en salud (IAAS) son causadas por hongos. De estas infecciones, el $70-90 \%$ son producidas por levaduras del género Candida [3]. La candidiasis invasora produce una elevada morbilidad y mortalidad, especialmente en Unidades de Cuidados Intensivos (UCls). La mortalidad cruda por candidiasis invasora va desde un 40 a un $60 \%$, relacionada en parte a la condición de base del paciente [3]. Entre los factores que incrementan el riesgo de candidiasis se encuentran la colonización por Candida, el largo de estadía en UCl, el uso de antibióticos de amplio espectro, la presencia de catéter venoso central, la Diabetes Mellitus, la nutrición parenteral, la ventilación mecánica, la neutropenia, el antecedente de cirugía (principalmente gastrointestinal), la profilaxis antifúngica, la insuficiencia renal, la hemodiálisis y la quimioterapia antineoplásica [3].

Los mecanismos de patogenicidad claramente identificados en $C$. albicans son: adherencia, dimorfirmo, «swich» 0 cambio fenotípico, formación de biopelículas y características de «fitness» 0 adaptación [4].

La siguiente revisión describe cómo $C$. albicans interactúa con el hospedero destacando sus principales mecanismos patogénicos, los mecanismos de reconocimiento, y la respuesta inmune innata asociada a su presencia.

\section{Mecanismos patogénicos de Candida albicans}

1. Adherencia: Es un mecanismo multifactorial en el que, utilizando varios tipos de adhesinas dependientes de su estado morfológico, C. albicans modifica su adherencia a distintas superficies. La máxima expresión de adherencia de esta levadura es la formación de biopelículas en el hospedero, que persé constituye un mecanismo patogénico [4].

Las adhesinas más importantes son aquellas tipo aglutinina (Als) miembros de una familia de ocho proteínas glicosiladas, genéticamente relacionadas, pero de gran variación alélica (Als1 a Als7 y Als9). Mutaciones en estas adhesinas, se asocian a una importante disminución en la virulencia de $C$. albicans $[5,6]$. De estas proteínas Als3 es especialmente importante en adherencia [4].

2. Dimorfismo (morfogénesis): La morfogénesis de C. albicans se define como la transición de la forma levaduriforme unicelular, a la forma filamentosa (pseudohifas o hifas) (Figura 1) [7]. La transición de la forma de levadura a hifas se ve facilitada por determinados nutrientes, un $\mathrm{pH}$ cercano al neutro, una temperatura de $37^{\circ} \mathrm{C}$, una concentración de $\mathrm{CO}_{2}$ de aproximadamente $5,5 \%$, la presencia de $\mathrm{N}$-acetî-Dglucosamina, suero, ciertos aminoácidos y biotina. La transición inversa a partir de las hifas hacia la forma de levadura puede ser provocada por bajas temperaturas, pH ácido, la ausencia de suero y una mayor concentración de glucosa [8, 9]. Dos genes importantes para la regulación de la morfogénesis en C. albicans son TUP1, EFG1 [10].

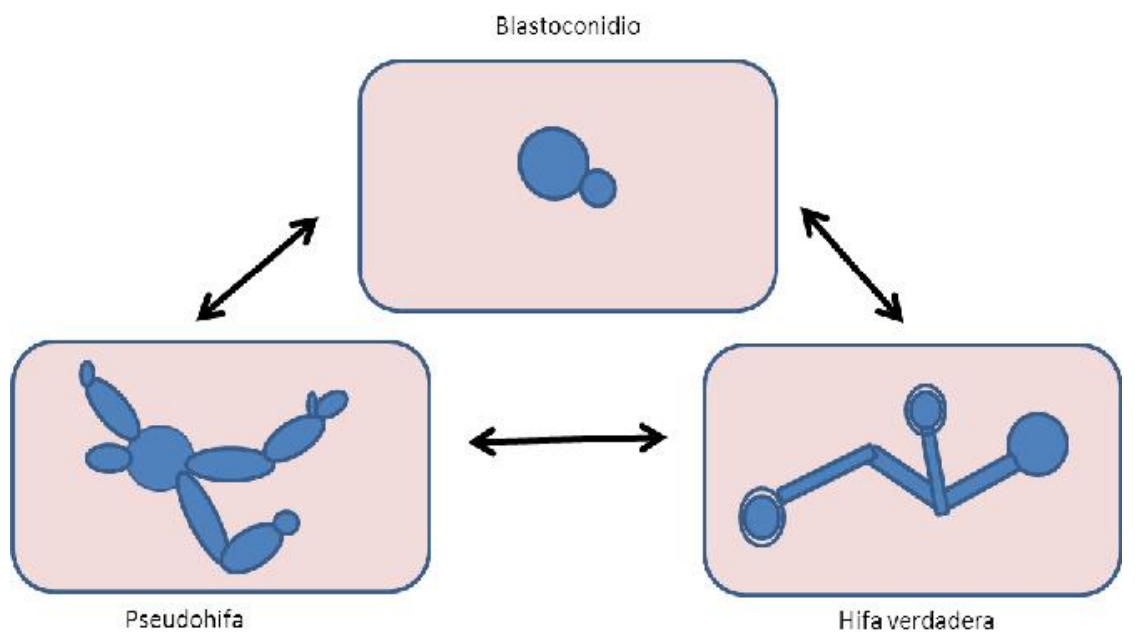

Figura 1. Morfogénesis de $C$. albicans.

La figura muestra la transición morfológica reversible que experimenta entre blastoconidio, pseudohifa e hifa verdadera. Adaptado del artículo «Morphogenesis and cell cycle progression in Candida albicans», Berman J, 2006 
Interacción Candida albicans-Hospedero: un proceso complejo en el que la inmunidad innata juega un importante papel - Tapia et al.

3. Invasión: La secreción de proteinasas es fundamental para degradar las barreras del tejido y obtener nutrientes en el sitio de la infección. Las proteinasas aspárticas secretadas o Saps de $C$. albicans hidrolizan proteínas del hospedero tales como, albumina, queratina, hemoglobina, colágeno, laminina, fibronectina, lactomucina, interleuquina $1 \beta$ $(\mathrm{IL}-1 \beta)$, cistatina A, e inmunoglobulina A (IgA) [12]. Dentro de la familia Sap, se han descrito diez proteínas (Sap1 a Sap10) y son responsables de la invasión tisular. La producción de Saps además se correlaciona con la formación de hifas, adherencia y el cambio fenotípico $[13,14]$. In vitro las Saps 1 , 2 y 3 se expresan en la fase de blastoconidio, mientras que Sap4, Sap5 y Sap6 se expresan en la fase de hifas $[15,16]$. Por su parte Sap9 y 10 se expresan en ambas fases de $C$. albicans [17]. Las isoenzimas Sap1 y Sap3, se expresan en infecciones orales y vaginales más que en la portación [16].

Las fosfolipasas son enzimas que hidrolizan enlaces ésteres de glico-fosfosfolípidos y, por lo tanto, contribuyen con la invasividad de $C$. albicans en el tejido. C. albicans expresa cuatro tipos fosfolipasas: $A, B, C$ y $D$ [18], siendo la $B$ la más importante, teniendo un rol clave en los procesos infecciosos [19]. Todas poseen actividad hidrolasa, pero además también poseen actividad lisofosfolipasa transacilasa capaz de liberar ácidos grasos a partir de fosfolípidos y luego transferir un ácido graso libre de lisofosfolípidos a otro fosfolípido [20]. Un trabajo en el que se compararon cepas de $C$. albicans aisladas del torrente sanguíneo con cepas aisladas de cavidad oral de voluntarios sanos, se demostró que las cepas invasoras produjeron una significativa mayor actividad de fosfolipasa extracelular que las cepas comensales [21].

\section{Inmunidad Innata y C. albicans}

Hasta hace poco tiempo, se sabía muy poco acerca de cómo macrófagos y neutrófilos, células importantes de la inmunidad innata, reconocían $C$. albicans como patógeno o cómo la interacción hongo-leucocito gatillaba una respuesta inmune $[22,23]$. Además se consideraba a la respuesta inmune innata como una respuesta primitiva y no sofisticada. Actualmente se sabe que este sistema no sólo reconoce diversos tipos de microorganismos, sino inicia y modula la respuesta inmune adaptativa mediada por células (linfocitos) T y B que interactúan con células presentadoras de antígeno, tales como las células dendríticas [22].

Los tipos celulares que participan en la inmunidad innata frente a $C$. albicans son: las células epiteliales y las células fagocíticas (polimorfonucleares neutrófilos y monocitos-macrófagos y células dendríticas). En el reclutamiento y activación de estas últimas, participan diversas citoquinas proinflamatorias y además hay factores solubles involucrados como el sistema de complemento y anticuerpos. Recientemente se ha descrito que células epiteliales orales y vaginales pueden inhibir el crecimiento de $C$. albicans de manera contacto-dependiente. Aunque las citoquinas proinflamatorias producidas por las células epiteliales, no tienen un efecto antifúngico directo, éstas sirven como señales para las células inflamatorias de las mucosas para potenciar su función antifúngica. Otras moléculas importantes en la respuesta inmune innata son las $\beta$-defensinas secretadas por las células epiteliales capaces de inactivar a $C$. albicans, lo cual será discutido posteriormente [1].

El reconocimiento de $C$. albicans en su estado patogénico para activar una respuesta por parte del hospedero se realiza a través de receptores (PRRs), que reconocen estructuras conservadas llamadas patrones moleculares asociados a patógenos PAMPs.

\section{Conformación de la pared celular de C. albicans y su reconocimiento por el hospedero}

La pared celular de $C$. albicans es un organelo dinámico, requerido para la forma celular, protección contra el ambiente, y para el reconocimiento por el sistema inmune innato del hospedero. Aunque es una estructura robusta, es también flexible. Los 3 principales polisacáridos presentes son la quitina, los glucanos y los mananos, que se encuentran organizados en dos láminas o capas: 1) la capa externa, altamente rica en 0-y $\mathrm{N}$ - polímeros de manosa (mananos) que están asociados covalentemente con proteínas para formar glicoproteínas y 2) la capa interna, que contiene quitina y $\beta$-1,3-glucano, constituyentes el esqueleto de la pared [24, 25] (Figura 2).

Las proteínas de la capa externa de la pared están ancladas a la capa interna predominantemente por glicosilfosfatidilinositol (GPI), y otras están vinculadas a la estructura a través de $\beta$-1,6-glucano que le otorga una mayor flexibilidad [22, 25, 26]. 


\section{C. albicans}

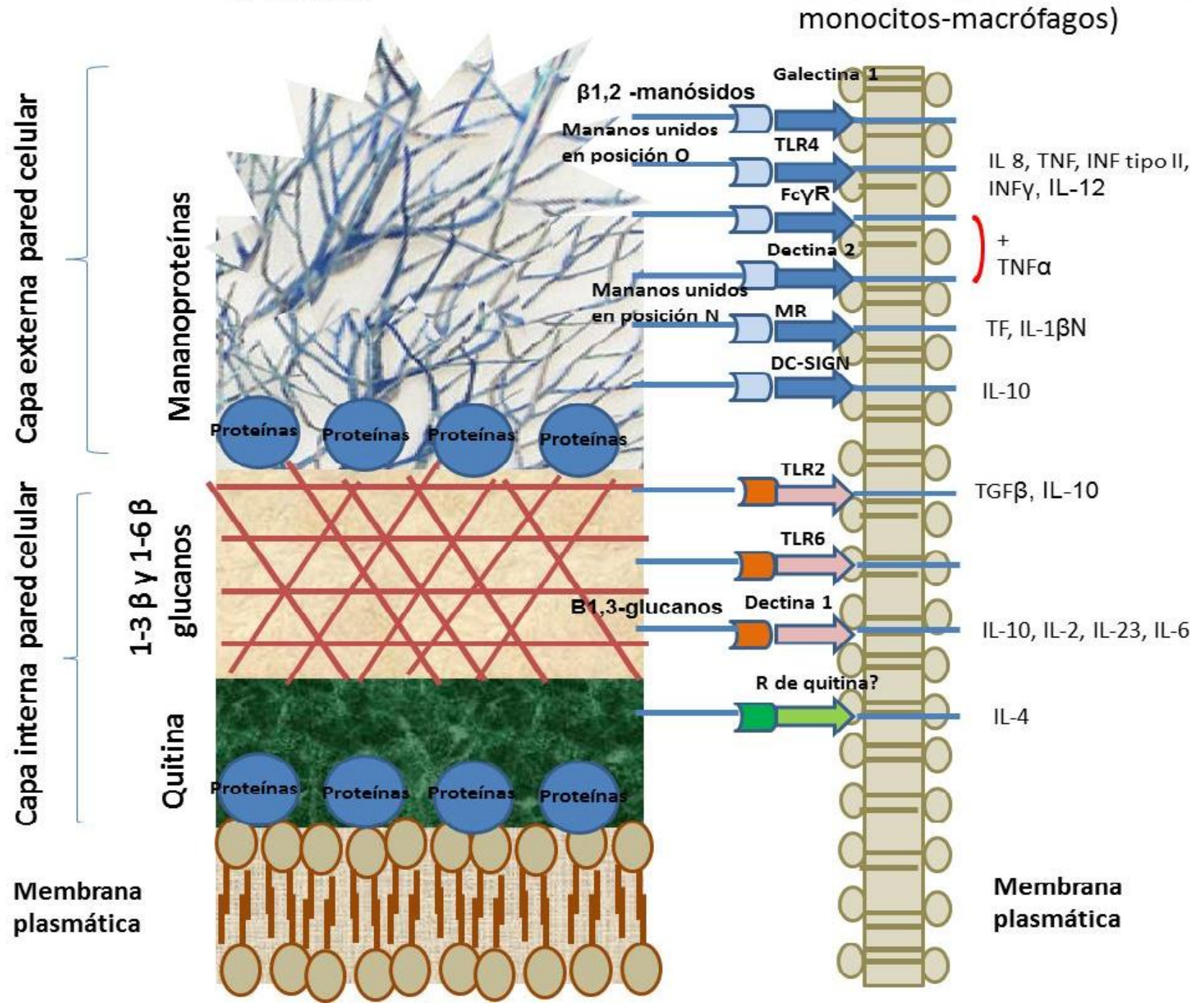

Figura 2. Estructura de la pared de $C$. albicans y la activación de PRRs por los diferentes PAMPS de C. albicans. Modificado del artículo «Role of cell wall polysaccharides during recognition of Candida albicans by the innate immune system», Pérez-García, 2011.[27]

A pesar que los componentes básicos de la pared celular de blastoconidias e hifas de $C$. albicans, el proteoma de la superficie y las cantidades individuales de patrones moleculares asociado a patógenos (PAMPs) difieren considerablemente. Por ejemplo, los mananos que decoran las proteínas de pared celular presentan menos enlaces fosfodiéster, $\beta-1,2$ mano-oligosacáridos en hifas, además de otras propiedades [25]. Además, en hifas existe un mayor contenido de quitina (3 a 5 veces más que blastoconidias). Aunque el contenido de $\beta$-1,3-glucano es similar entre blastoconidias e hifas de $C$. albicans, éste se encuentra más expuesto en la superficie de hifas [25]. La Figura 2 muestra los diversos PAMPS de $C$. albicans y su reconocimiento por receptores de reconocimiento de patrones (PRRs) en el hospedero (Figura 2) [22, 28].

El reconocimiento de $C$. albicans se realiza a través de PRRs que se activan con distintas estructuras; Ios $\beta$-glucanos son reconocidos por TLR2 en complejo con dectina 1 , los residuos 0 -manosa activan a TLR 4, los residuos N-manosa son reconocidos por CLR, específicamente por el receptor mannosebinding lectin (MBL) [28]. Otros receptores asociados al reconocimiento son: galectina, 3 dendritic cellspecific ICAM3 grabbing non-integrin (DC-SIGN), dectina 1, dectina 2, macrophage-inducible $\mathrm{C}$ type lectin (MINCLE), macrophage mannose receptor 1 
Interacción Candida albicans-Hospedero: un proceso complejo en el que la inmunidad innata juega un importante papel - Tapia et al.

(MR) y por último, receptores intracelulares tipo dominio de oligomerización de unión a nucleótidos (NOD). El receptor NLR family pyrin domaincontaining 3 (NLRP3) forma parte del inflamasoma y tiene un importante rol en la defensa del hospedero frente a $\mathrm{C}$. albicans.

Además de las mananoproteínas, mananos y â-glucanos, otras estructuras de $C$. albicans pueden ser reconocidas como PAMPS. La quitina es un polisacárido menos estudiado, que también forma parte de la pared celular. Se sabe que la quitina induce el reclutamiento de células inmunes, que liberan principalmente IL-4 e IL-13. Hay poca información en la literatura acerca del reconocimiento de este polímero (Figura 2)[22].

\section{Otros componentes de $C$. albicans reconocidos por el sistema inmune innato}

El ácido desoxiribonucleico (ADN) de hongos es pobremente metilado en comparación al ADN de mamíferos. Este ADN es reconocido por el sistema inmune, como ADN no propio a través de TLR9. Se sabe que linfocitos T CD4+ de ratones «knockout» para TLR9, producen mayores niveles de IL-4 y menores niveles de INF $\gamma$, comparado con linfocitos de ratones «wild type» después de la estimulación con C. albicans [22].

\section{Células involucradas en el reconocimiento fúngico a través de PRRs}

Las principales células del sistema inmune innato que reconocen patógenos invasores son monocitos y neutrófilos en circulación, junto con los macrófagos de tejidos. Los monocitos expresan altos niveles de TLRs en sus membranas y moderados niveles de LRs (receptores de lectina). Durante su diferenciación a macrófagos, ellos retienen la expresión de TLR, pero sobre-expresan fuertemente los LRs. Las células dendríticas, fundamentales en la presentación de antígenos, expresan la mayoría de los PRRs involucrados en el reconocimiento fúngico. Por su parte los neutrófilos expresan modeladamente Ios TLRs y fuertemente los receptores fagocíticos como el receptor de complemento 3 (CR3). Y los receptores $\mathrm{FC} Y$ ( $\mathrm{FC} \gamma \mathrm{Rs}$ ). Recientemente se ha descrito que células no profesionales de la respuesta inmune como queratinocitos y melanocitos expresan PRRs que reconocen $C$. albicans. En estudio reciente en nuestro laboratorio, demostramos que tanto queratinocitos como melanocitos de piel, expresan TLR2 y TLR2 y que reconocen diferencialmente $C$. albicans. Ambos tipos de células fueron capaces de discriminar la forma patogénica de $C$. albicans (hifa), a través de TLRs [29].

\section{Activación de la respuesta defensiva por PRRs}

La estimulación de PRRs por C. albicans activa diferentes vías de transducción de señales, que son redundantes y que derivan en la estimulación de citoquinas (Figura 2), fagocitosis y la muerte fúngica. Actualmente se sabe que muchos de los PRRs no sólo reconocen PAMPs específicos, sino modulan la respuesta inmune.

La fagocitosis de $C$. albicans es mediada por receptores opsónicos y no opsónicos. La unión y activación de la vía alternativa del complemento es importante para la quimiotaxis y opsonización de $C$. albicans, sin embargo, no es relevante en la lisis de esta levadura, debido al grosor de la pared celular. Por otra parte las lectinas unidoras de manosa aunque se unen y reconocen a $C$. albicans tienen un rol menor en la ingesta (fagocitosis) de $C$. albicans.

Varios receptores de membrana contribuyen con la fagocitosis de $C$. albicans, dentro de los cuales se encuentran dectina 1, MR y DC-SIGN (específico de células dendríticas). Aunque los TLR no participan directamente en la fagocitosis, parecen estar involucrados en la maduración de fagosoma.

En la muerte fúngica, han sido involucrados dectina 1 (en el estallido respiratorio), TLRs (facilitando el estallido respiratorio) y galectina 3 (involucrada en la muerte extracelular de C. albicans) [22].

En la activación de citoquinas, hay al menos 4 TLRs involucrados (TLR2, TLR4, TLR6 y TLR9). Luego del reconocimiento de estructuras microbianas, ellos activan las vías NFkB y MAPK. El balance entre las señales inducidas por TLR2 y TLR4 tiene un rol crucial en la regulación de la respuesta inmune (Figura 3). TLR4 induce una fuerte respuesta proinflamatoria a través de 2 vías: 1 ) «myeloid differentiation primary response gene 88» (My D88)-Mal que media producción de citoquinas a través de la inducción de NFkB y 2) la vía del «interferon regulatory factor» (IRF3). Aunque TLR2, también induce una respuesta proinflamatoria, ésta es más débil que la respuesta a la unión de TLR4. Se sabe que los ligandos de TLR2 fallan en inducir la liberación de IL-12 y e INFy, de la respuesta tipo «T helper $1 »\left(T_{H} 1\right)$, favoreciendo una 
respuesta $T_{H} 20$ «regulatory $T$ cell « $\left(T_{\text {reg }}\right)$. Esto es avalado por un estudio en el que zimozán (extracto de pared celular de S. cerevisiae) induce el desarrollo de una población de células dendríticas tolerogénicas , a través de TLR2 y dectina 1. La inducción de una respuesta tolerogénica depende de «extracelular signal related kinase (ERK)/fosforilación de MAPK, un mecanismo distinto al de la vía p38/Jun-N-terminal kinase (JNK) que es inducida por la estimulación de TLR4. Ratones «knockout para TLR2 son más resistentes a la infección por $C$. albicans, debido a una preponderancia de una respuesta $T_{H} 1$.C. albicans induce inmunosupresión a través de la liberación de IL10, gatillada por la activación de TLR2 (Figura 3) [22].

El rol de TLR6 y TLR9 en la inducción de citoquinas es menos prominente. Aunque TLR2 y TLR6 se encuentran como heterodímero, que reconoce a zimozán, la inducción de citoquinas es sólo moderadamente reducida en ratones knockout para TLR6. La ausencia de TLR9 se traduce en una ligera disminución de la producción de citoquinas hacia un perfil antiinflamatorio [22]

Los receptores dectina 1 y dectina 2 y MR han sido implicados en el inicio de la respuesta frente a $C$. albicans. Se sabe que dectina 2 se une preferencialmente a la forma de hifa induciendo TNF $\alpha$ y al agonista del receptor de IL1 (IL-1Ra). Por otra parte dectina 1 induce la producción de numerosas citoquinas y quimioquinas en respuesta a hongos, incluyendo TNF $\alpha$, macrophage inflammatory protein 2 (MIP2), macrophage inflammatory protein $1 \alpha$, granulocyte-macrophage-colony-stimulating factor (GM-CSF), IL-10, IL-12, IL- $1 \alpha$, IL-1 $\beta$, IL-23 e IL-6. Mientras la producción de IL-10, IL-6 e IL-2 es mediada exclusivamente por dectina 1, la inducción de citoquinas pro-inflamatorias y quimioquinas requiere de la activación de TLR2, a través de una cascada de señales colaborativa.

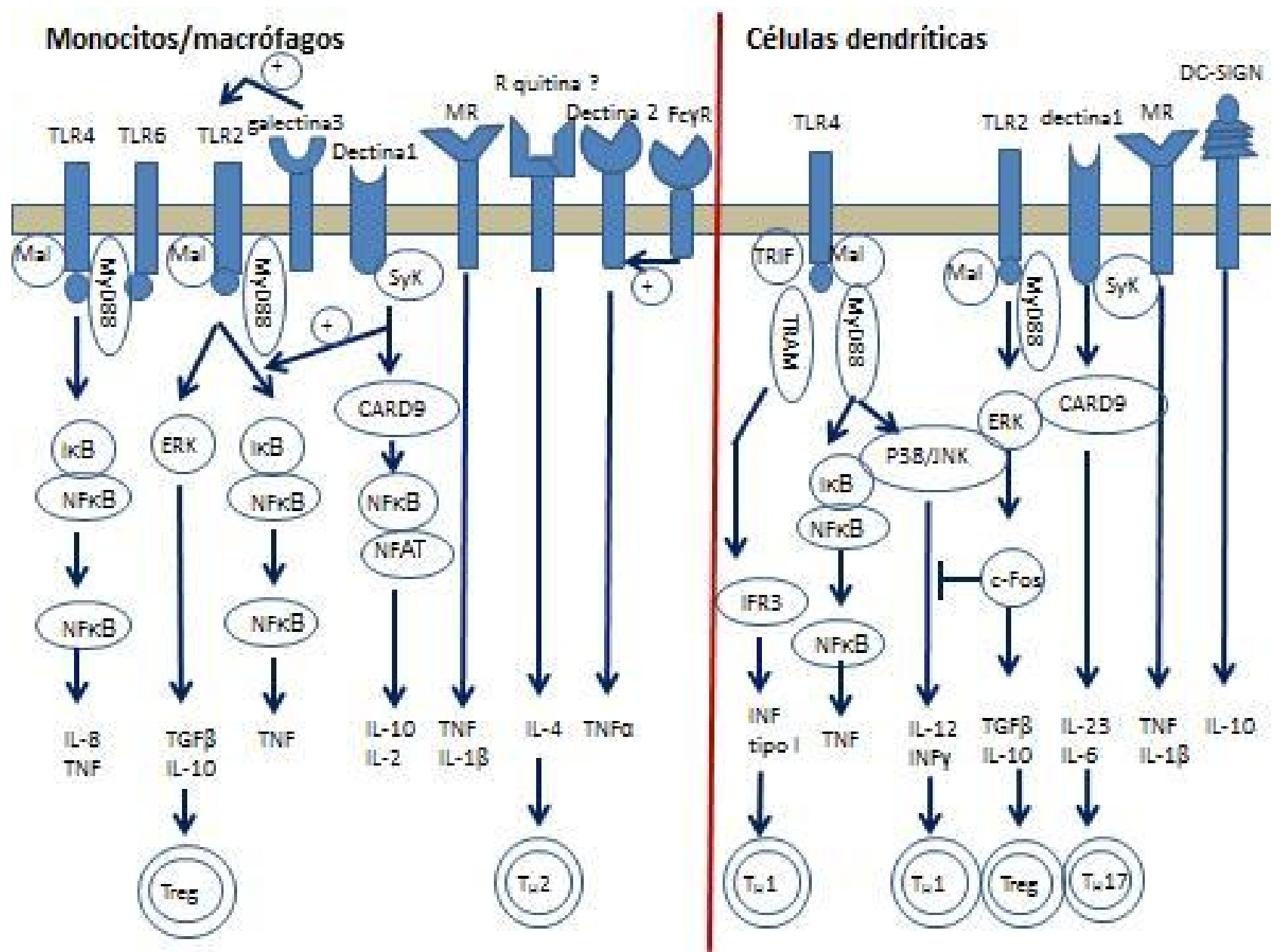

Figura 3. Cascada de señales activadas por la estimulación de los diversos PRRs en monocitos/ macrófago y células dendríticas. Adaptado del artículo «An integrated model of recognition of Candida albicans by the innate immune system», Netea et al., 2008[22]. 
La señalización intracelular inducida por dectina 1, involucra el reclutamiento de $S y k^{46}$, y una señalización río abajo vía CARD9. La vía dectina 1Syk-CARD9, induce la maduración directa de las células dendríticas y dirige una respuesta tipo $\mathrm{T}_{4} 17$, de manera independiente a la activación de TĹRs (Figura 3). Esto se ha asociado a la activación por hifa de C. albicans. El rol de IL-17 en candidiasis diseminada es protector por la inducción del reclutamiento de neutrófilos. Por otra parte CARD9 funciona como molécula adaptadora que media señales pro-inflamatorias inducidas por otros receptores como nucleotide-binding oligomerization domain (NOD)-like receptors, ITAM-associated receptors y probablemente TLR. También se sabe que la vía TRIF modula el balance entre las respuestas $T_{H} 17$ deletérea y $T_{\text {reg }}$ protectora en ratones con candidiasis gástrica[22].

\section{Discriminación entre C. albicans comensal y patógeno por la célula epitelial}

Discriminar entre el estado comensal y patógeno de $C$. albicans es fundamental para mantener la homeostasis o para activar una respuesta defensora por parte del hospedero. Las células epiteliales pueden modular la respuesta innata de $C$. albicans a través de la activación del factor nuclear kappa B (NF-kB), factor de transcripción que juega un papel importante en la expresión de genes relacionados con la respuesta inflamatoria durante la infección por $C$. albicans. En una primera fase, a los 30 minutos de exposición, la activación de NF-kB depende de la vía MAPK (mitogen activated protein kinase) y del factor transcripcional c-Jun, y es independiente de la morfología de $C$. albicans (Figura 4). En una segunda fase, a las 2 horas de contacto, la activación de MAPK conduce a la activación MKP1 y de c-Fos, lo cual es dependiente de la presencia de hifas y de la carga fúngica correlacionándose con una respuesta pro-inflamatoria (Figura 4). De esta manera, frente a una baja carga fúngica, el epitelio no libera citoquinas, mientras, cuando se expone a una alta carga fúngica y/o a la forma filamentosa de $C$. albicans (como ocurre en una infección) se activa una respuesta específica y de mayor magnitud. Por esta razón la activación de MAPK/ MKP1/c-Fos representa un "vía de respuesta al peligro"' que es fundamental para identificar y responder al cambio desde el comensalismo al estado patogénico [30-32].

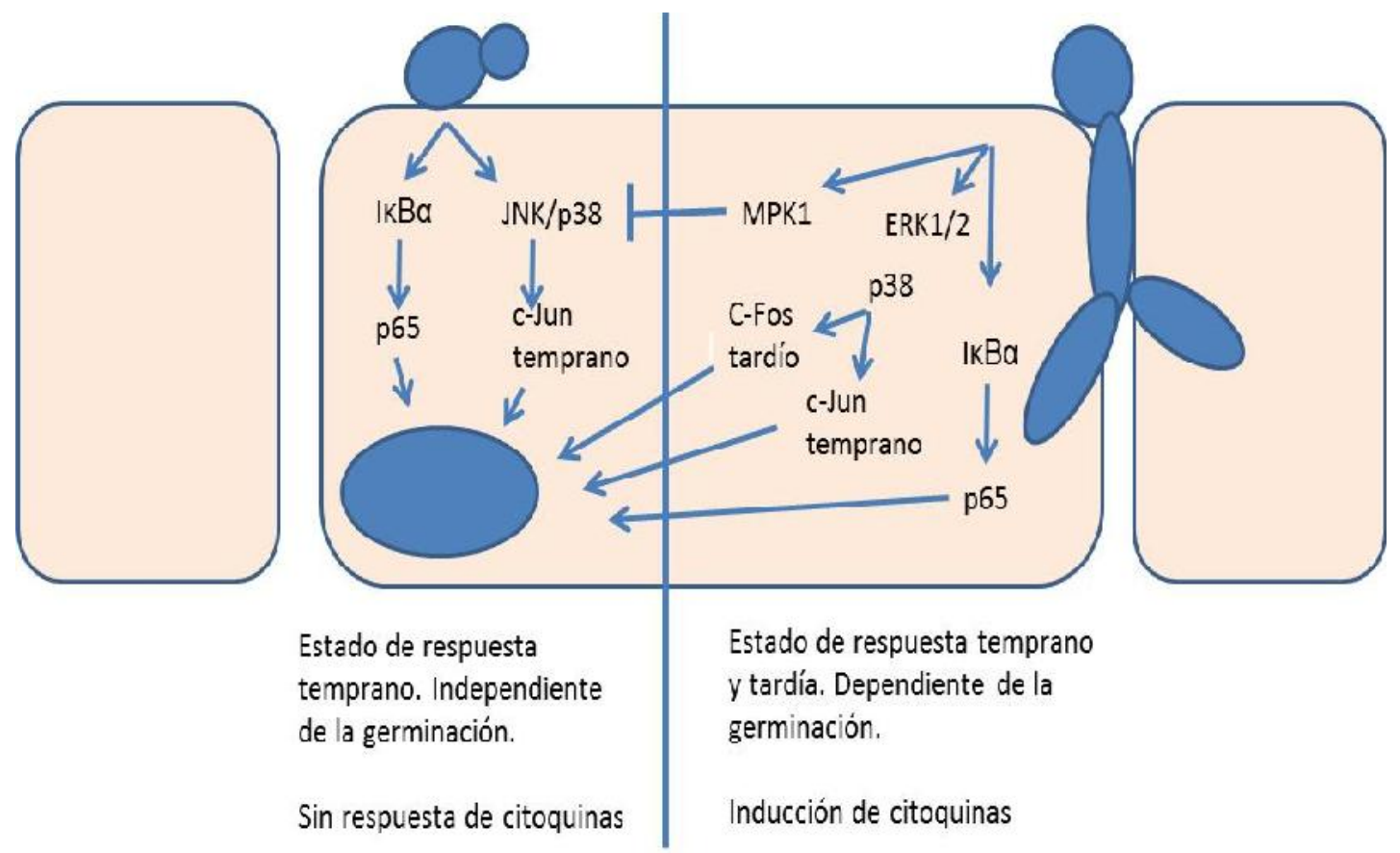

Figura 4. Respuesta bifásica de la célula epitelial en contacto con $\boldsymbol{C}$. albicans. Se observan las vías diferencialmente activadas en la célula epitelia por células fúngicas colonizantes y células invasoras. Las levaduras inducen la subunidad p65 de NF-êB y c-Jun temprano en ausencia de respuesta de citoquinas. En contraste, las hifas estimulan p65 y c-Jun temprano además de estimular la fosfatasa MKP-1, MAPK y c-Fos tardío, resultando en la potente liberación de citoquinas. Adaptado de «Epithelial sensing of fungal invasión» de Netea et al., 2010. [32]. 
Interacción Candida albicans-Hospedero: un proceso complejo en el que la inmunidad innata juega un importante papel - Tapia et al.

Por otra parte, la formación de hifa, ha sido un evento clave para la activación del inflamasoma y la activación de IL-1ßen macrófagos murinos. Aunque IL-1 $\beta$ es indispensable para la diferenciación $T_{H} 17$, el reconocimiento de la hifa invadiendo, es un paso crucial para que los macrófagos discriminen colonización de invasión. La hifa de Candida específicamente activa el inflamasoma mediante la exposición de PAMPs fúngicos como â-glucanos que originalmente se encuentran encubiertos en la fase levaduriforme, como se discutirá más adelante. La activación del inflamasoma y la producción de IL-1â son fundamentales para la diferenciación $\mathrm{T}_{\mathrm{H}} 17$, con la subsecuente producción de II-17.

\section{Rol de las $\beta$-defensinas en la inmunidad innata}

Son pequeños péptidos catiónicos de 12 a 50 aminoácidos con actividad antimicrobiana contra bacterias y hongos y además, algunas pueden actuar como quimioatractantes de células $T$ y células dendríticas $[33,34]$. Pueden ser clasificadas de acuerdo a su estructura en $\alpha$-defensinas, $\beta$-defensinas y $\theta$-defensinas. Las $\alpha$-defensinas son predominantemente encontradas en neutrófilos y células de Paneth del intestino delgado, mientras que las $\beta$ defensinas se han aislado de leucocitos y células epiteliales. Se han identificado alrededor de $28 \beta$ defensinas humanas [34].

Las $\beta$-defensinas humanas (HBD) más estudiadas y que presentan mayor variabilidad de respuesta frente a distintas condiciones son HBD-1, HBD-2 y HBD-3. La expresión de las $\beta$-defensinas es constitutiva e inducible por citoquinas proinflamatorias (IL-1 $\beta$ y TNF- $\alpha$ ) que aumenta la expresión de HBD-2 y por IFN- $\gamma$ y compuestos bacterianos como LPS aumentan la expresión de HBD-1 y HBD-3. [33, $35,36]$.

HBD-1 es expresada en el epitelio del intestino delgado, páncreas, riñón, próstata, testículo, vagina, ectocérvix, endocérvix, útero, trompas de Falopio, placenta y timo. HBD-2 es expresada en queratinocitos de mucosa gingival, piel y epitelio traqueal $[35,36]$. HBD-3 es expresada en queratinocitos y tejidos de las amígdalas.

HBD-2 es capaz de destruir $E$. coli y otras bacterias gram negativas, mientras que HBD-2 tiene actividad antifúngica contra $C$. albicans y la HBD-3 contra $C$. albicans y Saccharomyces cerevisiae. Se ha determinado que una dosis de $25 \mathrm{~g} / \mathrm{mL}$, es capaz de reducir un $90 \%$ las unidades formadoras de colonia de C. albicans, a diferencia de su efectos bacteriostático sobre Staphylococcus aureus y otros Gram positivos que requieren a concentraciones tan altas como $100 \mathrm{~g} / \mathrm{mL}$ para ser eliminados [34].

\section{Evasión de la respuesta inmune por parte de $C$. albicans}

En su estado comensal C. albicans debe sobrevivir al sistema defensivo del hospedero, al $\mathrm{pH}$ local y debe adquirir nutrientes y además competir con otros microorganismos de la microbiota. Para ello, C. albicans utiliza varias estrategias para escapar y evadir los mecanismos defensivos del hospedero [1].

A continuación se detallan algunas estrategias del hongo para evadir la respuesta inmune

\section{a. Transición de fase de levadura a hifa}

C. albicans es considerado por muchos un hongo dimórfico, en el sentido que puede pasar de un hongo levaduriforme a hifa. Como se señaló previamente, el cambio 0 «switch» morfológico entre la fase de levadura y la fase de hifas se considera su principal factor de virulencia. La formación de hifas eventualmente conduce a la perforación («pearcing») y la muerte de los macrófagos por las hifas de $C$. albicans, pero la forma de levadura también es necesaria para su diseminación en la infección sistémica [1, 4].

\section{b. Invasión de epitelios}

C. albicans invade la barrera epitelial a través de dos mecanismos diferentes: 1) invasión tisular activa y 2) endocitosis pasiva inducida. En el primer mecanismo, las hifas ingresan a las células epiteliales invadiendo el tejido [1].

Muchos genes asociados a la formación de hifas, incluyendo ALS3, HWP1, ECE1, SOD5, PHR1 y PRA1 están sobre-expresados en $C$. albicans en contacto con células epiteliales, lo cual puede estar relacionado a la capacidad de penetración activa de la forma de hifa en la célula epitelial. Por otra parte se sabe que ALS-3 de C. albicans simula la función de las caderinas del hospedero induciendo una endocitosis a través de su unión a E-caderina de las células epiteliales orales. Una vez dentro de la célula epitelial provoca la perforación de la célula con la participación del gen EED (epitelial escape and dissemination). Además $C$. albicans es capaz de reducir la expresión de TLR4 con un subsecuente incremento de la vulnerabilidad de la célula epitelial a la infección por esta levadura [1]. 


\section{Escape de la fagocitosis:}

\section{Encubrimiento de los PAMPs de la superficie.}

Como ase vio anteriormenye, para ser fagocitada, $C$. albicans requiere ser reonocida por el hospedero. Un mecanismo a través del cual se previene el paso de reconocimiento es el encubrimiento de los PAMPs. Se sabe que los âglucanos se encuentran encubiertos por los componentes de pared externa de la célula fúngica (Figura 2), evitando así el reconocimiento de dectina1 [1, 22]. Mutantes deficientes en mananos unidos en la posisión 0 y N son más fácilmente fagocitados por macrófagos. Cuando $C$. albicans es dañada por el hospedero, estos $\beta$-glucanos se exponen lo cual da cuenta de la constante batalla entre hospedero y patógeno frente a una infección por $C$. albicans.

\section{Inhibición y degradación del complemento}

C. albicans posee varias estrategias para interferir con la activación del complemento, con el fin de evitar la fagocitosis o para reducir la producción de citoquinas proinflamatorias. Se ha demostrado que las SAPs degradan C3b y así inhiben la opsonización de Candida. C. albicans es capaz de unirse al regulador $\mathrm{Cb} 4$-bindig protein, al factor H, FHL-1 y la proteína unidora de plasminógeno con el fin de inhibir la acción del sistema del complemento. La proteína Pra1 de la superficie de C. albicans, se une al factor $\mathrm{H}$ y a la $\mathrm{C} 4 \mathrm{~b}$-binding protein, para regular la activación del complemento. Sin embargo, esta proteína sirve como ligando primario, reconocido por $\mathrm{C} 3$, facilitando la fagocitosis. Nuevamente se pone de manifiesto la compleja interacción hongo-hospedero, en el cual, cada uno utiliza bien sus armas [1].

\section{Inhibición de la formación del fagolisosoma}

Un importante paso en el proceso de eliminar a un patógeno es la fusión del fagosoma que contiene el microorganismo con los lisosomas. $C$. albicans es capaz de modular el tráfico de membranas intracelulares inhibiendo la formación del fagolisosoma. Este paso es dependiente de la viabilidad fúngica y se relaciona con la capacidad de producir hifas. Además hay cariotipos de $C$. albicans más resistentes a la muerte intracelular en el fagolisosoma. El conocimiento de estos mecanismos puede ser de utilidad para el desarrollo de nuevos compuestos antifúngicos [1].
Inhibición de especies reactivas de oxígeno (ROS)

La producción de ROS es el mayor mecanismo antifúngico en los fagocitos. Para contrarrestar el estrés oxidativo Candida posee varios mecanismos defensivos como la activación de catalasas (CAT) y superoxido dismutasas (SOD) de superficie. Aunque el reconocimiento de la pared celular de $C$. albicans es necesario para la producción de ROS, se requiere viabilidad de $C$. albicans para neutralizarlos. Se sabe que además la capacidad de $C$. albicans de generar vacuolas, le confiere resistencia al estrés oxidativo y favorece el crecimiento como hifas.

\section{Farnesol}

Farnesol fue identificado por primera vez como una molécula de «quorum de sensing» 0 «conversación celular» que reprime la transición desde la fase de levadura a hifa de $C$. albicans como una forma de autorregulación. Actualmente se considera que farnesol es un factor de virulencia de C.albicans ya que por una parte, disminuye la viabilidad de los macrófagos y por otra, protege a $C$. albicans del estrés oxidativo mediante la inducción de una sobre-expresión de los genes CAT1, SOD1, SOD2 y SOD4 en la levadura.

\section{d. Modulación de la producción de citoquinas por factores solubles.}

Aunque se conoce mucho de los mecanismos por los cuales $C$. albicans induce la producción de citoquinas en el hospedero, el cómo esta levadura explota la producción de citoquinas para su propio beneficio, ha sido poco explorado. Se sabe que levadura inhibe la producción de IL12 e IFNy en células mononucleares de sangre periférica. El efecto inhibitorio de $C$. albicans, depende de la viabilidad de C. albicans y se ha asociado a la secreción de glicoproteínas y a la activación extracelular de la vía ERK/MAPK.

Se ha demostrado que factores solubles de $C$. albicans, recuperados de medio condicionado de crecimiento, pueden amplificar la producción de IL-6 e IL-8 en el hospedero, además de disminuir la síntesis de IFNy por la sobre-expresión de IL-10. De esta manera se desvía la respuesta protectora $T_{H} 1$ hacia una respuesta deletérea $T_{H} 2$ [1]. En un estudio realizado en nuestro laboratorio, demostramos que al estimular queratinocitos de piel con hifas inactivadas de $C$. albicans a las $24 \mathrm{~h}$ de estimulación se observó una evasión de la respuesta inmune a través de la fuerte inducción de IL-10, lo cual no se observó con blastoconidias inactivadas [37]. 


\section{a. Inhibición de la producción de IL-17}

Se ha demostrado que IL-17 es un componente importante de la defensa del hospedero frente a la infección por Candida. Algunos componentes de la pared celular de $C$. albicans como $\beta$-glucanos, son reconocidos por Ios receptores CLR (tipo lectina tipo C), como MR, dectina 1 y dectina 2 (Figura 2), conduciendo a la activación del inflamasoma, producción de IL-1 $\beta$ y la subsecuente inducción de IL-17. Se ha descrito que $C$. albicans es capaz de inhibir IL-17 del hospedero mediante una alteración del metabolismo del triptófano. El metabolismo del triptófano es regulado por dos enzimas diferentes: indolamina 2,3-dioxigenasa (ID0) y triptófano hidroxilasa. Al inhibir la expresión de ID0, C. albicans puede cambiar el metabolismo del triptófano, disminu yendo las quinureninas y aumentando los metabolitos 5-hidroxitriptófano. El incremento en los niveles de 5-hidroxitriptófano inhibe la producción de IL-17 por el hospedero[1].

\section{CONCLUSIONES}

En los últimos años los mecanismos mediante los cuales el sistema inmune innato reconoce y responde a $C$. albicans, se han ido dilucidando poco a poco reconociéndose que no se trata de un sistema primitivo, sino sofisticado y eficiente. Por otra parte el conocimiento de los mecanismos patogénicos de $C$. albicans ha permitido conocer mejor su interacción con el hospedero. Esta interacción es compleja y probablemente en una infección en pacientes es más compleja aún. Aún hay preguntas sin responder, como por ejemplo cómo la célula epitelial educa al sistema inmune innato para luchar contra la infección fúngica o cómo se comunica («cross talking») con las células inmunes. También, sería importante estudiar el rol comensal de $C$. albicans en las mucosas y si en este estado, la levadura ejerce un efecto inmunomodulador.

\section{AGRADECIMIENTOS}

A los estudiantes José Amaro, Marisol Fuentes y Mary Anne Falconer, por su apoyo en el desarrollo de nuestra línea de investigación. Al proyecto Fondecyt 1110160, que permitió contribuir con 2 trabajos citados en este artículo.

\section{REFERENCIAS}

1. Cheng, S.C., et al. (2012) Interplay between Candida albicans and the mammalian innate host defense. Infect. Immun. 80: 1304-1313.

2. Trick, W.E. and W.R. Jarvis. (1998) Epidemiology of nosocomial fungal infection in the 1990s. Rev. Iberoam. Micol. 15: 2-6.

3. Delaloye, J. and T. Calandra. (2013). Invasive candidiasis as a cause of sepsis in the critically ill patient. Virulence. 5:1-9.

4. Mayer, F.L., D. Wilson, and B. Hube (2013). Candida albicans pathogenicity mechanisms. Virulence. 4:119-128.

5. Zhao, X., S.H. Oh, and L.L. Hoyer (2007). Unequal contribution of ALS9 alleles to adhesion between Candida albicans and human vascular endothelial cells. Microbiology. 153: 2342-2350.

6. Hoyer, L.L., et al. (2008) Discovering the secrets of the Candida albicans agglutinin-like sequence (ALS) gene family—a sticky pursuit. Med. Mycol. 46:1-15.

7. Brown, A.J.P., S. Argimón, and N.A.R. Gow. (2007). Signal Transduction and Morphogenesis in Candida albicans, in Biology of the Fungal Cell, R. Howard and N.R. Gow, Editors., Springer Berlin Heidelberg. pp.167-194.

\section{Corner, B.E. and P.T. Magee. (1997) Candida} pathogenesis: unravelling the threads of infection. Curr Biol. 7 :R691-R694.

9. Eckert, S.E., et al. (2007). PGA4, a GAS homologue from Candida albicans, is up-regulated early in infection processes. Fungal Genet Biol. 44: 368-377.

10. Liu, H. (2001). Transcriptional control of dimorphism in Candida albicans. Curr. Opin. Microbiol. 4: 728-735.

11. Berman, J. (2006). Morphogenesis and cell cycle progression in Candida albicans. Curr. Opin. Microbiol. 9: 595-601.

12. Hube, B., et al. (1998). Functional aspects of secreted Candida proteinases. Exp. Med. Biol. 436:339-44.

13. Monod, M. and Z.M. Borg-von (2002), Secreted aspartic proteases as virulence factors of Candida species. Biol. Chem. 383:1087-93. 
14. Naglik, J.R., S.J. Challacombe, and B. Hube (2003) Candida albicans secreted aspartyl proteinases in virulence and pathogenesis. Microbiol. Mol. Biol. Rev. 67: 400-428.

15. Sudbery, P.E. (2011). Growth of Candida albicans hyphae. Nat. Rev. Microbiol, . 9:737-748.

16. Naglik, J., et al. (2004). Candida albicans proteinases and host/pathogen interactions. Cell. Microbiol. 6: 915-926.

17. Albrecht, A., et al. (2006). Glycosylphosphatidylinositol-anchored proteases of Candida albicans target proteins necessary for both cellular processes and hostpathogen interactions. J. Biol. Chem. 28: 688-694.

18. Schaller, M., et al. (2005). Hydrolytic enzymes as virulence factors of Candida albicans. Mycoses. 2005. 48: 365-77.

19. Ying, S. and L. Chunyang. (2012). Correlation between phospholipase of Candida albicans and resistance to fluconazole. Mycoses. 55: 50-55.

20. Theiss, S., etal. (2006). Inactivation of the phospholipase $B$ gene PLB5 in wild-type Candida albicans reduces cellassociated phospholipase A2 activity and attenuates virulence. Int. J. Med. Microbiol. 296: 405-420.

21. Ibrahim, A.S., et al. (1995) Evidence implicating phospholipase as a virulence factor of Candida albicans. Infect. Immun. 63: 1993-1998.

22. Netea, M.G., et al. (2008) An integrated model of the recognition of Candida albicans by the innate immune system. Nat Rev Microbiol. 6: 67-78.

23. Abbas, A.K., A.H.H. Lichtman, and S. Pillai. (2011). Cellular and Molecular Immunology: with STUDENT CONSULT Online Access. Elsevier Health Sciences.

24. Hall, R.A. and N.A. Gow (2013) Mannosylation in Candida albicans: role in cell wall function and immune recognition. Mol. Microbiol.1-15.

25. Gow, N.A.,etal. (2012) Candida albicans morphogenesis and hostdefense: discriminating invasion from colonization. Nat. Rev. Microbiol. 10:112-122.

26. Romani, L. (2011). Immunity to fungal infections. Nat. Rev. Immunol. 11: 275-288.
27. Perez-Garcia LA, D.-J.D., Lopez-Esparza A, MoraMontes HM. (2001). Role of cell wall polysaccharides during recognition of Candida albicans by the innate immune system. J. Glycobiol. 1: 1-7.

28. Netea, M.G., et al. (2006). Immune sensing of Candida albicans requires cooperative recognition of mannans and glucans by lectin and Toll-like receptors. J Clin. Invest.116: 1642-1650.

29. (2012). Abstracts of the 18th Congress of the International Society for Human and Animal Mycology. June 11-15, 2012. Berlin, Germany. Mycoses. 55 (Suppl 4): $1-355$.

30. Moyes, D.L., et al. (2010), A biphasic innate immune MAPK response discriminates between the yeast and hyphal forms of Candida albicans in epithelial cells. Cell Host Microbe. 8: 225-235.

31. Moyes, D.L., et al. (2012). Activation of MAPK/CFos induced responses in oral epithelial cells is specific to Candida albicans and Candida dubliniensis hyphae. Med. Microbiol. Immunol. 201: 93-101.

32. Netea, M.G. and B.J. Kullberg. (2010). Epithelial sensing of fungal invasion. Cell Host. Microbe. 8: 219-220.

33. Joly, S., et al. (2005). Correlation between betadefensin expression and induction profiles in gingival keratinocytes. Mol. Immunol. 42: 1073-1084.

34. Schneider, J.J., et al. (2005), Human defensins. J. Mol. Med. (Berl). 83: 587-595.

35. Mathews, M., et al.(1999). Production of betadefensin antimicrobial peptides by the oral mucosa and salivary glands. Infect. Immun. 67: 2740-2745.

36. Krisanaprakornkit, S., et al. (2000). Inducible expression of human beta-defensin 2 by Fuso-bacterium nucleatum in oral epithelial cells: multiple signaling pathways and role of commensal bacteria in innate immunity and the epithelial barrier. Infect Immun. 68: 29072915.

37. (2013). Abstracts of the LASID (Latin American Society for Immunodeficiencies) Meeting 2013. October 17-19,. Santiago, Chile. J. Clin. Immunol. 33: S105-S139.

\section{CONFLICTO DE INTERESES}

Los autores declaran no tener conflicto de intereses. 